Anuario del Instituto de Historia Argentina, vol. 17, n² 2, e048, diciembre 2017.

ISSN 2314-257X

Universidad Nacional de La Plata.

Facultad de Humanidades y Ciencias de la Educación.

Centro de Historia Argentina y Americana

\title{
Puertas y llaves. Reconfiguración de los vínculos entre gobernadores y vecinos en Buenos Aires a partir de las reformas borbónicas tempranas
}

\section{Doors and Keys. Reconfiguration of the relations between governors and neighbors in Buenos Aires from the early Bourbon reforms}

\section{Carlos María Birocco}

Universidad Nacional de La Plata, Argentina | cmbirocco@hotmail.com

\section{PALABRAS CLAVE RESUMEN}

Cabildo Hasta la primera década del siglo XVIII, las relaciones de poder político se estructuraban en Buenos Aires en torno al vínculo entre el gobernador y un sector de los vecinos, compuesto por los miembros de una parentela local o por un conjunto de acólitos no emparentados entre sí. Eso generó enfrentamientos de

Facciones facciones en el Cabildo, donde tendrían lugar la confrontación y negociación política. Pero desde 1715 la Corona confió la Gobernación del Río de la Plata a militares de prestigio que recibieron directivas para poner fin a la lucha facciosa. Uno de ellos, Bruno Mauricio de Zavala, intentaría someter al cabildo a través de la resignificación del empleo de teniente de gobernador, no sin generar la resistencia de sus integrantes.

\section{KEYWORDS ABSTRACT}

Cabildo Until the first decade of the eighteenth century, power relations were structured in Buenos Aires around the link between the governor and a section of neighbors, composed by members of a local kinship or a group

Politics

Factions

Pererrogatives and privileges of acolytes unrelated to each other. This generated clashes of factions in the Cabildo, where confrontation and political negotiations would take place. But since 1715 the crown entrusted the Governorship of the Rio de la Plata to prestigious military officers who received directives to put an end to the factional struggle. One of them, Bruno Mauricio de Zavala, would try to subdue the Cabildo through the resignification of the position of teniente de gobernador, not without generating the resistance of its members.

Recibido: 20 de spetiembre de 2017 I Aceptado: 28 de noviembre de 2017 I Publicado: 15 de diciembre de 2017

Cita sugerida: Birocco, C. M. (2017). Puertas y llaves. Reconfiguración de los vínculos entre gobernadores y vecinos en Buenos Aires a partir de las reformas borbónicas tempranas. Anuario del Instituto de Historia Argentina, $17(2)$, e048. https://doi.org/10.24215/2314257Xe048 


\section{Buenos Aires en el Virreinato del Perú}

“Continuamente comercian con la Colonia de Portugueses, trayendo las crecidas conducciones de ropa que caminan desde Buenos Aires hasta Potosí, espacio de 500 leguas sin tener en todo él un soldado que embarace tan segura y pacífica transgresión”. La cita, que alude a la desenfadada libertad con que los comerciantes porteños introducían mercancías de contrabando en las provincias andinas, proviene del libelo Estado político del Reino del Perú, que circuló en Lima en la primera mitad del siglo XVIII. Su autor se había propuesto exponer las causas de la corrupción del sistema administrativo español y exigir que se implantaran reformas (Brennot, 1989, pp. 170-172). Sin embargo, si lo escogimos como punto de partida fue por un motivo diferente: sus páginas nos brindan un sugerente sistema de representaciones que nos permite comprender cómo era entendida la política económica de la Monarquía por uno de sus súbditos americanos. El océano Pacífico, sobre el que se recostaba el Virreinato del Perú, fue descripto en ellas como una “caja cerrada” que pertenecía al soberano español de un polo al otro. Pero la hermeticidad de ese mare clausum había sido objeto de fisuras a través de las cuales los metales preciosos escapaban al circuito monopólico en dirección a otras naciones europeas. Para dar un nombre a esas brechas, el libelista recurrió a otra metáfora: las llamó puertas. Dos eran, en efecto, las "puertas relajadas por donde se manejan las entradas de ropas y salidas de tesoros”: Panamá y el Río de la Plata. Desde las costas del istmo, el comercio ilegal con los ingleses permitía que se fugasen anualmente unos 500.000 pesos en plata. Pero Buenos Aires era considerada un punto de fuga de una envergadura aún mayor, pues el intercambio que sostenían los porteños con "la opulenta Colonia de los Portugueses” causaba la evasión de “todos los caudales del Potosí y todos los de Chile”. Se estimaba que gracias al tráfico ilícito con la Colonia do Sacramento salían anualmente 1.100 .000 pesos anuales en plata hacia Europa $\underline{1}$.

El Estado político del Reino del Perú testimoniaba el deterioro en que se hallaba el régimen de navegación atlántica que habían impuesto los Habsburgo a sus dependencias americanas, el cual no sería objeto de retoques por parte de Felipe V, primer soberano de la dinastía de Borbón, hasta una etapa bastante tardía de su reinado. Al canalizarse el grueso del tráfico ultramarino a través del costoso sistema de flotas y galeones, el puerto de Buenos Aires quedaba relegado a una posición marginal en la carrera de Indias. Desde que se impidió a sus habitantes el uso de embarcaciones propias para el tráfico marítimo, los navíos de registro se habían convertido en su único canal legal de intercambios con la metrópoli. Se trataba de embarcaciones que se movían en grupos muy reducidos uniendo éste y otros puertos americanos con Sevilla o con Cádiz. La Casa de Contratación les franqueaba la habilitación a cambio de contraprestaciones, como lo eran la de trasportar a un gobernador con su comitiva, o a partidas de soldados, o bien la de entregar expedientes judiciales y correspondencia oficial. Entre 1648 y 1697, Buenos Aires sería visitado por treinta de dichos navíos, a los que se sumaron otros treinta entre 1698 y 1740: a partir de estas cifras puede deducirse una afluencia promedio de dos navíos cada tres años. Pero ese flujo distó mucho de ser regular. Durante la Guerra de Sucesión, por ejemplo, la conexión con la península adoleció de significativos altibajos, al punto de que entre 1705 y 1711 ninguna embarcación procedente de Cádiz se hizo presente en el estuario.

La Monarquía manifestó una actitud ambigua en relación a Buenos Aires. Intentó, por un lado, dejarla apartada de los principales canales de circulación de metales preciosos, restringiendo su 
participación en la navegación oceánica y entorpeciendo el radio de sus transacciones terrestres por medio de la colocación de aduanas secas. Semejante cercamiento pretendía dificultarle a los porteños el acceso a la plata amonedada que necesitaban para pagar las mercancías europeas que recibían en su trato clandestino con portugueses y holandeses. Pero no logró impedir el flujo de la plata altoperuana hacia el puerto de Buenos Aires, sino que, por el contrario, éste experimentaría un decidido crecimiento a partir de las últimas décadas del siglo XVII, sustentado en el envío de tropas de mulas, ganado vacuno y carretas cargadas de yerba o de textiles europeos a las regiones andinas centrales (Moutoukias, 1988, pp. 62-73). Por otra parte, como la Corona se había propuesto convertir a Buenos Aires en un bastión militar que defendiera el contrafuerte sur del virreinato del Perú, sólo pudo solventar la presencia de una guarnición en esta ciudad ordenando la transferencia de metálico desde las mismas cecas de Potosí. Ésta se realizaba a través del sistema del Real Situado, por el que los militares de los presidios recibían su pagamento desde el lugar en que era acuñada la moneda ${ }^{2}$. Esas remesas de plata distaron de llevarse a cabo con regularidad -se conocieron demoras de más de siete años en ser despachadas-, pero aun así no deben ser subestimadas como uno de los canales por los que se monetarizó esta plaza.

Desde que en 1680 una armada portuguesa desembarcó en la rivera opuesta del estuario y fundó la Colonia do Sacramento, la Monarquía redobló su interés en militarizar Buenos Aires. Hacía ya más de una década que ese era uno de los objetivos de la administración de los Habsburgo, que habían recurrido desde 1667 a los navíos de registro para trasportar a esta ciudad refuerzos de soldados y armamento. En las últimas dos décadas de ese siglo, la guarnición llegó a disponer entre 800 y 900 efectivos, un cuarto de los cuales obtendría el rango de oficiales. Todos ellos fueron colocados bajo la jefatura de un comisario militar, el Cabo y Gobernador de la Caballería del Presidio, cargo que fue creado en 1680 con el fin de evitar que se produjera una vacancia en la conducción militar de esta provincia si el gobernador muriera o debiera abandonar imprevistamente su puesto. Pero reformas como ésta, cuyo fin era precaver los casos de acefalía y reafirmar las cadenas de mando, se concentrarían en el ordenamiento jerárquico y no tendrían sino una débil proyección en el plano material. La endeble infraestructura de las fortificaciones de Buenos Aires no sería objeto de mejoras hasta la década de 1710, por lo que el fuerte de San Baltasar de Austria, que además de ser la sede de la oficialidad del Presidio servía de residencia al gobernador y a su familia, siguió siendo un mediocre castillejo hecho de adobe que estaba deficientemente preparado para resistir una descarga de artillería.

Aunque no invirtiera en sostener la infraestructura defensiva de este puerto, la Corona no dejaba de ser consciente de la endeblez de su posicionamiento en el extremo meridional de Sudamérica. Por tal razón, envió al Río de la Plata a gobernadores con reconocida experiencia militar, en casi todos los casos lograda en la guerra contra los franceses en Flandes. Entre 1630 y 1680, aquellos que ocuparon el empleo por orden del Consejo de Indias eran dueños de una foja de destacados servicios militares, independientemente de que alguno hubiera llegado al puesto gracias a la venalidad (Trujillo, 2012, pp. 204-205). Desde la década de 1670 -aprovechándose del relajamiento de los controles ejercidos por la Monarquía en las últimas décadas del período Habsburgo-, los gobernadores gozarían de una libertad cada vez mayor a la hora de tomar decisiones, algo que por otra parte se explicaba por la imposibilidad que éstos tenían de someterlas con agilidad a la consulta de sus superiores inmediatos, los virreyes del Perú, quienes residían a una enorme distancia. 
Ese poder discrecional, que la Monarquía puso poco empeño en moderar, les serviría además para avanzar sobre las facultades del cabildo de Buenos Aires y despojarlo del control de uno de los escasos recursos de que disponía como corporación: el control sobre la venta de cueros en el puerto. Por medio de una real cédula, el Consejo de Indias autorizó en 1677 a los capitanes de los navíos de registro a contactarse en forma directa con los vecinos para proveerse de corambre, por lo que impidió al Ayuntamiento encabezar las negociaciones y retener una parte de las utilidades de esas transacciones, como se había acostumbrado hacer hasta entonces. Este vacío permitió que los gobernadores se interpusieran como mediadores obligados en ese tráfico, y forzaran a los cargadores de los navíos a pactar con ellos las cuotas de corambre que se les permitiría embarcar y el precio por unidad. Más tarde le arrebatarían al Cabildo otra facultad: la de autorizar las vaquerías o expediciones de cacería de ganado cimarrón. El ayuntamiento se resistiría a este despojo y presentaría sus reclamos ante la Real Audiencia de Chuquisaca y el Consejo de Indias, pero pasarían más de treinta años antes de que esas facultades le fueran restituidas por la Corona. En tanto, no le quedó a la vecindad otro recurso que aliarse a los gobernadores para sacar rédito de la corrupción administrativa, por lo que un sector de la misma se volcaría efectivamente a hacerlo.

A lo largo de este trabajo nos proponemos mostrar cómo se conformaron influyentes camarillas en torno a los gobernadores hasta la llegada de Bruno Mauricio de Zavala, que acabaría con esos vínculos de proximidad y ejercería una vigilancia más estrecha sobre la oligarquía local. Este artículo pretende ser un aporte a la comprensión de un período escasamente estudiado, como es el de la transición entre los Habsburgo y los Borbones, en especial en relación a la Gobernación del Río de la Plata. La nueva dinastía se había propuesto desde su arribo al trono modernizar la estructura administrativa, y dar fin a la venalidad de los cargos, pero al verse acuciada por los abrumadores gastos de sus continuos emprendimientos bélicos no le fue posible llevar a cabo reformas de consideración hasta avanzado el siglo XVIII. En Buenos Aires, sin embargo, veremos a la Corona intervenir para frenar la lucha facciosa e imponer una reestructuración de la jerarquía militar. Asimismo, se revitalizarían a nivel local las medidas de control sobre la vecindad y el Cabildo.

\section{Alianzas entre gobernadores y facciones locales (1691-1715)}

Con anterioridad a 1715, las relaciones de poder se estructuraron en Buenos Aires en torno al vínculo entre el gobernador y un sector muy acotado de vecinos. Ese sector pudo estar compuesto por los miembros de una parentela local, o bien por un conjunto de acólitos no necesariamente emparentados entre sí. La primera de estas modalidades pudo apreciarse durante los gobiernos de Agustín de Robles (1691-1700) y Alonso de Valdés Inclán (1702-1708), pero se hizo sobre todo visible mientras se llevó a cabo la pesquisa de Juan Joseph de Mutiloa (1712-1714). La segunda fue característica de los gobiernos de Manuel de Velasco y Tejada (1708-1712) y de Alonso de Arce y Soria (1714). Las camarillas que rodeaban a los gobernadores fueron un significativo nodo de poder informal, con una proyección tanto política como económica, que a veces se solapaba a poderes formales ya constituidos como el Cabildo o la plana mayor del Presidio. Entre quienes las conformaban, se destacaba con frecuencia el privado del gobernador. Se trataba de un vecino que pertenecía a la parentela o facción favorecida por éste, que lo secundaba en sus asuntos públicos y 
personales y a quien se confería el rol de intermediador con el resto de la vecindad $\stackrel{3}{\text {. }}$

Durante la gestión de Agustín de Robles fue notoria la relación de proximidad que éste sostuvo con una prestigiosa parentela porteña: los Báez de Alpoin. Se trataba de un linaje que, aunque originario de Portugal, era muy antiguo en el Río de la Plata y contaba con ramificaciones en Santa Fe y Corrientes. (Gammalson, 1980, pp. 187-189). Juan Báez de Alpoin, miembro de la segunda generación nacida en Buenos Aires, asumiría la dirección de los asuntos familiares a lo largo de casi dos décadas, pero la compartió con una segunda figura no menos significativa: el general Miguel de Riblos, el esposo de una de sus primas. Este último había llegado a Buenos Aires en una leva de soldados desde su Navarra natal, pero fue ascendido a oficial y se enriquecería gracias al comercio de mulas con las provincias andinas (Birocco, 1996). Con él mantuvo Robles los vínculos más estrechos, al punto de encargarle el manejo de los almacenes donde se proveía a los militares del Presidio.

Debido a que la llegada del pagamento desde las Reales Cajas de Potosí solía retrasarse a veces por años, los gobernadores anteriores a Robles habían montado un sistema de distribución de provisiones y vestuario a soldados y oficiales. Éstos recibían vales a cuenta de sus futuros sueldos que solamente podían ser canjeados en los almacenes que se les señalaban para ello. Al serle encargado el abastecimiento de la totalidad de las compañías de la guarnición, Riblos recibía una sustanciosa prebenda, ya que cuando el situado llegase a Buenos Aires los sueldos pasarían directamente a sus arcas. Para hacer más explícitos los privilegios que le confirió, Robles lo nombró en junio de 1697 comisario de la caballería del Presidio, lo que equivalía a ponerlo a cargo de la fortaleza y a dejar acreditada su aptitud para ejercer el eventual interinato de la Provincia ${ }^{4}$. Aunque lo mantuvo en el puesto por el brevísimo lapso de tres días, este empleo militar se conservaría en el interior del clan, ya que fue reemplazado en el ejercicio de ese comisariado por su pariente, Juan Báez de Alpoin, quien lo ocupó hasta comienzos del siglo siguiente.

El gobernador que reemplazó a Agustín de Robles, Manuel de Prado y Maldonado (1700-1702) se destacó por su excepcionalidad: desmontó la red de vínculos creada por su predecesor y no recreó una red sustitutiva. Pero éste sería sucedido por Alonso de Valdés Inclán, quien al igual que Robles sostuvo un vínculo privilegiado con una de las principales parentelas de la ciudad. Se trató en este caso de los Samartín, linaje criollo que se hallaba profusamente emparentado con otras familias prominentes y cuyos miembros habían ocupado con frecuencia escaños en el cabildo (Birocco, 2011a). Al igual que los Báez de Alpoin, este clan contaba con dos figuras rectoras: el maestre de campo Juan de Samartín, un criollo reconocido por sus servicios militares pero también por su participación en los empleos concejiles, pues había sido alcalde ordinario y procurador del cabildo, y su cuñado, el portugués Antonio Guerreros, quien también se había desempeñado como alcalde ordinario en tres ocasiones y se había enriquecido gracias a su participación en el comercio atlántico. Este último se convertiría en el privado de Valdés Inclán, quien no sólo le encargaría el aprovisionamiento de las ocho compañías de la guarnición, a las que se obligó a proveerse en su tienda mediante el acostumbrado sistema de vales canjeables, sino también el aprovisionamiento de las tropas que en 1704 asediaron Colonia del Sacramento.

La alianza entre Valdés Inclán y los Samartín sería, sin embargo, de corta vida. En julio de 1705, en el marco de la Guerra de Sucesión, Felipe V dispuso una represalia contra los bienes de todos los 
portugueses que vivían en sus dominios americanos, a causa de lo cual Guerreros fue apartado del abastecimiento de las tropas, y las mercaderías de sus almacenes fueron incautadas. Ejecutando esta medida, Valdés Inclán pudo desembarazarse de esta parentela, que probablemente no se mostró dispuesta a obedecer mansamente sus requerimientos. Guerreros fue reemplazado en su rol de privado por Antonio Meléndez de Figueroa, un comerciante, que aunque no contaba con cuantiosos bienes, tampoco se hallaba vinculado en forma tan estrecha a los linajes más poderosos de la ciudad, lo cual lo convertía en alguien más maleable al propósito del gobernador de enriquecerse a costa de los suministros a la soldadesca y del tráfico ilícito.

Durante el gobierno de Valdés Inclán se efectivizó el Tratado del Real Asiento con Francia, por el cual un consorcio negrero, la Compagnie de Guinée, obtuvo licencia para establecer sus oficinas en Buenos Aires y desembarcar esclavos en este puerto. Durante la Guerra de Sucesión Española ingresaron algo más de medio centenar de embarcaciones francesas en el Río de la Plata, aunque en su mayor parte no eran buques pertenecientes a dicho consorcio. Algo más de la mitad de ellos se sirvieron de Buenos Aires como puerto de paso en su trayecto hacia el Pacífico: tras denunciar desperfectos técnicos en sus naves, declararon haberse visto forzados a concluir su viaje en nuestro estuario, o bien permanecieron en él con el pretexto de solucionarlos. Como una real cédula había otorgado en 1701 a los franceses el derecho de realizar arribadas forzosas, los gobernadores debían franquearle el permiso de invernar en el puerto, adquirir bastimentos o hacer reparaciones antes de continuar con su viaje. Pero en su mayor parte se trató de arribadas maliciosas, esto es, del fingimiento de un pedido de socorro para poder desembarcar mercancías en forma clandestina (Jumar, 2000, 240-247).

En 1704 arribaron a Buenos Aires los primeros buques franceses y Valdés Inclán les exigió en concepto de sobornos una porción de los textiles que éstos escondían en sus bodegas, parte de los cuales remitió a los almacenes que administraba su privado, Antonio Meléndez de Figueroa, para que fueran repartidos a cambio de vales a los soldados. El resto lo entregó a un mercader altoperuano, Antonio de la Tixera, quien lo condujo a Potosí y obtuvo utilidades por valor de 160.000 pesos. A los capitanes de navío que no se sometían a sus imposiciones les aplicó medidas punitorias, como la confiscación de sus cargamentos, y consiguió de esa manera que el grueso de las mercancías contrabandeadas se canalizara por un circuito que se encontraba bajo su dominio. Estos manejos serían denunciados por el clan de los Samartín, quienes, desde que fueron apartados de la camarilla del gobernador, se convirtieron en sus opositores. Se habían atrincherado en el cabildo, donde se conformó en torno a ellos una facción que presentó varias denuncias contra Valdés Inclán en su juicio de residencia. La misma fue liderada por uno de los sobrinos del maestre de campo Juan de Samartín, Joseph de Arregui, quien en 1702 había ingresado a la corporación municipal tras haber subastado los empleos de regidor y alférez real.

De acuerdo con la normativa castellana, el juez de la residencia de Valdés Inclán sería su sucesor en el mando, Manuel de Velasco y Tejada, que había sido investido como gobernador en febrero de 1708. Éste se preocupó menos en escarmentar sus excesos que en mantener en funcionamiento el aparato que aquel había recreado para hacer rentable su cargo. Velasco se apropió del dispositivo que había montado Valdés Inclán para hegemonizar el tráfico clandestino con los franceses y convirtió a Meléndez de Figueroa en su privado, manteniéndolo en el manejo de los almacenes en 
los que se proveía a los militares del Presidio.

El clan de los Samartín se mantuvo en el Cabildo nucleando a la facción de vecinos que, tras haber denunciado a Valdés Inclán, enfrentó ahora a Velasco. En torno a este último, por su parte, se conformaría una camarilla cuyos miembros no se hallaban enlazados por medio del parentesco, sino mancomunados en su rechazo al rol hegemónico que venían desempeñando los Samartín en el gobierno municipal. El gobernador halló la manera de neutralizar aquel foco de oposición en el Ayuntamiento cesando en sus cargos a Arregui y a otros regidores aliados a éste, con el pretexto de que no habían hecho confirmar sus títulos por el Consejo de Indias, y en 1709 fraguó un remate de los empleos concejiles que habían quedado vacantes para colocar en ellos a los miembros de su camarilla. Como Arregui y otros de los perjudicados amenazaron con recurrir a la Real Audiencia de Chuquisaca para iniciarle pleito, Velasco los hizo encarcelar.

Noticiado de las arbitrariedades de Velasco y de su participación en el contrabando con los franceses, en 1712 Felipe V envió a Buenos Aires a un pesquisidor, Juan Joseph de Mutiloa y Andueza. Este recluyó al gobernador y lo sometió a juicio, a la vez que asumía provisoriamente el mando político y militar de la provincia. Asimismo, devolvió al ayuntamiento porteño el control sobre la venta de cueros a los capitanes de las embarcaciones, facultad que le había sido arrebatada por Velasco y sus predecesores. El pesquisidor establecería una alianza con el clan de los Samartín y con los miembros de la facción que se había conformado en torno a esa parentela, a quienes devolvió sus escaños en el Cabildo. Ellos lo secundarían cuando se propuso no traspasar el mando a quien la Corona había designado para suceder a Velasco, el coronel Alonso de Arce y Soria, y se demoró casi dos años en investirlo en el cargo que había adquirido por compra al Consejo de Indias. Durante esa coyuntura de tensión, los integrantes de la antigua camarilla de Velasco se agruparon en torno a Arce, sin duda con la expectativa de beneficiarse con esa relación de proximidad cuando éste asumiera el mando. Pero no lo conseguirían, ya que falleció en octubre de 1714, a escasas semanas de haber sido investido como gobernador.

A lo largo de la última década del siglo XVII y de la primera del siglo siguiente, en suma, los gobernadores del Río de la Plata no ocultaron su avidez por enriquecerse a expensas del cargo. A trabar fuertes lazos con algunas de las parentelas locales los guiaba el propósito de convertir en redituable su empleo, pues en éstas hallarían los conocimientos sobre las prácticas y el entorno que le permitiría maximizar los beneficios de la corrupción y la extorción, ofreciendo como contraparte una participación en ellos. Pero al favorecer a un sector de la vecindad y excluir a otros se exacerbaron las divisiones facciosas que ya existían en el seno de la misma. Gracias a esa conflictividad, el Cabildo de Buenos Aires -que podía ser tanto el órgano de representación de uno de los bandos en pugna como un espacio en disputa- ocuparía un lugar central en los procesos de confrontación y negociación política. En la segunda década del siglo XVIII, empero, dicha corporación perdería ese lugar destacado en el conjunto de las relaciones de poder

\section{Poniendo distancias: los gobernadores militares y el Cabildo (1715-1726)}

Durante la primavera de 1714, la lucha facciosa alcanzaría su cenit. El deceso de Arce y Soria incitó el enfrentamiento entre el bando que dominaba el Cabildo y la camarilla del difunto gobernador. En su lecho de muerte, éste había designado como sucesor a un militar de alto rango, el ingeniero 
artillero Joseph Bermúdez. El Ayuntamiento, dominado por el clan de los Samartín, se opuso a reconocerlo. Fundándose en la Recopilación de Leyes de los Reinos de Indias de 1681, esta corporación designó al alcalde ordinario Pablo González de la Cuadra para ejercer el mando político y otorgó al comisario de la caballería Manuel de Barranco Zapiáin el mando militar. Bermúdez se atrincheró con algunos acólitos en el fuerte, dispuesto a resistir, pero al no encontrar mayores apoyos en la vecindad acabó por rendirse y por reconocer a sus rivales (Tau Anzoátegui, 2003; Birocco 2011b).

Puesto al tanto de la virulencia de este enfrentamiento entre facciones, Felipe V quiso precaverse de que la oligarquía local provocara nuevos desórdenes. Por medio de una real cédula despachada por el Consejo de Indias el 16 de marzo de 1716, se creó el cargo de Teniente de Rey, que suplantó al de de comisario de la caballería y fue puesto al mando de todas las compañías de la guarnición de Buenos Aires. Se dispuso que en adelante fuera éste quien reemplazara al gobernador tanto en el mando político como en el militar en el caso de que se ausentase o muriese. Quedaban así invalidadas las disposiciones de la Recopilación de Leyes de Indias que conferían al Cabildo la facultad de asumir el poder político en casos de acefalía. Con ello, las competencias administrativas de esta corporación quedaban, a partir de entonces, reducidas al plano municipal.

No obstante, la principal medida tomada por este monarca fue la de sustraer al gobierno del Río de la Plata del lote de los empleos venales. Los referidos Manuel de Prado y Maldonado, Alonso de Valdés Inclán, Manuel de Velasco y Alonso de Arce y Soria habían comprado sus cargos a la Corona. Si nos remitimos a la terminología de la época, se decía que sus nombramientos habían sido "beneficiados": la compra de un empleo era considerada un servicio económico hecho al rey (Sanz Tapia, 2005). Estas transacciones, frecuentes en tiempos de los últimos Habsburgo, se continuaron durante los primeros años del reinado de Felipe V, y alcanzaron su momento más álgido entre 1705 y 1711 (Guerrero Elecalde, 2012). Pero los graves sucesos de 1714 moverían a este rey a volver a colocar esta gobernación en manos de militares de carrera. El primero de ellos fue Baltasar García Ros (1715-1717), quien debió supervisar la instalación del Real Asiento británico en Buenos Aires, y al que más tarde se le encargó la delicada misión de devolver la Colonia de Sacramento a los portugueses. Aunque su permanencia en el empleo fue breve, la corona no quiso renunciar a mantenerlo en su planta funcionarial y lo colocó en otro cargo de relevancia, el de teniente de rey.

Dos años más tarde, la gobernación era otorgada a Bruno Mauricio de Zavala (1717-1734). Al igual que García Ros, éste formaba parte de un notorio grupo de hombres de armas que habían mostrado probada fidelidad a la causa borbónica y se habían destacado por sus carreras exitosas y por su participación comprometida en las empresas bélicas del rey. No es un dato menor que tanto García Ros como Zavala fueran oriundos del noreste montañoso de la península: el primero era natural de la villa navarra de Valtierra, mientras que el segundo había nacido en Durango de Vizcaya. Durante la Guerra de Sucesión, un conjunto de notables de esa región había mostrado su lealtad al bando borbónico, por lo que fueron premiados con cargos y honores. Vinculados más tarde al programa reformista de Felipe V, un puñado de ellos logró ocupar lugares de influencia en la Corte y el resto escalaría posiciones en la alta oficialidad del Ejército y en la administración de los territorios de la Monarquía. Frecuentemente relacionados con la extracción y el tráfico de hierro, construyeron 
vastas redes de comercialización del metal gracias a la colocación de familiares y socios en los puertos de uno y otro lado del Atlántico. Así, el imperio hispánico ofreció a vascos y navarros la posibilidad de enriquecerse tanto en el servicio del rey como con la participación en el tráfico indiano. El secreto de su éxito, según se ha explicado, fue que identificaron sus propios intereses con los de la Corona (Guerrero Elecalde, 2012, pp. 77-80; Tarragó, 2010).

$\mathrm{Al}$ afincarse en Buenos Aires, Zavala acentuaría su pertenencia a esas redes paisanales. A diferencia de sus predecesores, que necesitaron recurrir a la alianza con las parentelas o facciones locales para poder lucrar con su cargo, este gobernador no se vio necesitado de ellas porque careció de ese cuestionado propósito. El círculo de sus allegados lo componían otros “cántabros”, como lo eran el teniente de rey Baltasar García Ros, el veedor del Presidio Blas de Gainza, el teniente de gobernador Antonio de Larrazábal y el suegro de éste, Gaspar de Avellaneda. Todos ellos provenían de Navarra y el País Vasco. El Cabildo de Buenos Aires entraría en tensión con esta red vincular al enfrentar abiertamente en 1724 al referido Larrazábal por un asunto de etiqueta concejil: éste tuvo la audacia de exhibirse en las ceremonias religiosas, a las que concurrió junto con los cabildantes, empuñando un bastón -emblema del poder militar- cuando en realidad su cargo era meramente político. Pero Zavala lo respaldaría a pesar de esa trasgresión y varios de los regidores resultarían expulsados del Ayuntamiento a causa de sus protestas.

\section{La resignificación de una magistratura local: el teniente de gobernador}

Bruno Mauricio de Zavala fue provisto de nuevos recursos para fortalecer la guarnición militar porteña. Llegó acompañado por un piquete de 300 soldados de infantería y por el ingeniero militar Domingo Petrarca, a quien se encargaría rediseñar las fortificaciones de la ciudad. Se le indicó que debía preservar a Buenos Aires de cualquier alteración, externa o interna, en atención a su relevancia en el sistema defensivo imperial. Relevancia que, atendiendo al sistema de representaciones de la Monarquía, haría que esta ciudad fuera concebida no como una puerta sino como una llave, es decir, como un dispositivo de obstrucción cuyo propósito era frenar el avance de las demás potencias europeas, tanto en lo territorial como en lo económico. En el instructivo que recibió al ser nombrado gobernador, en efecto, se le recalcó "la suma importancia de mantener aquella Plaza de Buenos Aires, llave de todo el Reyno del Perú, de suerte que siempre se halle preservada de cualquiera invasión de enemigos” (Tarragó, 2014, p. 46). La metáfora anteriormente utilizada -la de representar a Buenos Aires como una "puerta"- tenía inequívocas connotaciones negativas y resaltaba su condición de enclave marginal por medio del cual drenaba ilegalmente la plata potosina. Esa marginalidad había surgido del hecho de que la ciudad se encontrara alejada de los centros políticos y económicos de los grandes virreinatos y apartada del sistema de flotas y galeones, circunstancias que habían facilitado la alianza entre el gobernador de turno y algunos grupos locales con el fin de enriquecerse gracias al tráfico ilícito con holandeses, portugueses, franceses y británicos. En cambio, la idea de “llave”, reformulada por la nueva dinastía, sugería que ésta se había propuesto recuperar el control, de manera de poder regular el tráfico comercial de esa “puerta” en beneficio propio.

Ese paso en dirección a la militarización se dio en otras regiones igualmente expuestas del imperio hispánico. No fue casual que el nombramiento de Zavala fuera contemporáneo a la imposición de 
los Decretos de Nueva Planta en Cataluña, Valencia, Mallorca y Cerdeña, que propugnaban el establecimiento de una administración fuertemente militarizada en esos reinos (Giménez López, 1994, pp. 41-75). En Buenos Aires, la misma vendría acompañada de un reordenamiento en las jerarquías: en 1716, dos reales cédulas reformaron la cúpula de la plana mayor de la oficialidad local. Una de ellas, como ya hemos referido, creaba el cargo de Teniente de Rey, colocado a la cabeza de las ocho compañías rentadas de la guarnición. La otra reinstauraba un antiguo empleo militar: el de Veedor del Presidio. A éste se le encomendó que llevase la nómina de dichas compañías y que supervisara la distribución de suministros durante la revista de las tropas. Atento a los desfalcos al erario que los gobernadores venales, en consonancia con los oficiales de la Real Hacienda, habían cometido con la excusa de aprovisionar a las tropas, Felipe V dispuso que se regularizara la transferencia de los pagamentos a través del sistema del Real Situado, que a partir de 1717 fue remitido cada año a Buenos Aires. Al corresponderle al veedor la liquidación de los sueldos, los gobernadores y sus adláteres quedaron definitivamente apartados del lucrativo negocio del racionamiento a oficiales y soldados.

Zavala ensayaría, además, un reordenamiento de las jerarquías en la planta del cabildo porteño a través de la resignificación del empleo de Teniente de Gobernador. Se trataba de un funcionario que era nombrado por el mismo gobernador para que lo representase ante dicha corporación, pero también para que lo auxiliara en asuntos administrativos como los de fiscalizar las entradas y salidas de carretas o visitar las tiendas y pulperías para que sus propietarios se compusieran con la Real Hacienda. Ocasionalmente podía delegarle funciones de justicia: cuando no podía desempeñarse como juez de apelaciones en los tribunales ordinarios, esa tarea recaía teóricamente en su teniente, aunque en Buenos Aires muy rara vez se lo viera cumpliéndola $\underline{5}$. Estaba facultado, por último, para ejercer un control sobre la población indígena local: examinaba las contratas de trabajo de los indios libres y debía garantizar que, en la reducción de Santa Cruz de los Quilmes, el servicio de mita se observara "en la conformidad que se ha estilado", con el fin de que los mitayos que pasaban a trabajar a la ciudad asistieran con preferencia a las viudas y vecinos pobres.

El protocolo concejil asignaba al teniente de gobernador un importante rol: el de convocar a las sesiones del Cabildo. Según rezaba el título que se otorgó a uno de ellos, tenía encomendado "llamar y juntar [a] los capitulares y regidores para hacer los acuerdos y cabildos ordinarios y particulares para tratar las cosas tocantes al servicio de Su Majestad y bien común de esta República”ㅌ. Las Ordenanzas de Buenos Aires, sancionadas en 1668, prohibían a la corporación sesionar sin la presencia del teniente de gobernador, y en el caso de que estuviese enfermo o ausente debía dejarse razón de ello en el libro de acuerdos. No obstante, esa prohibición fue pocas veces respetada. Años más tarde, el regidor Gregorio Ramos Mejía, autor de una breve historia de los oficios concejiles, destacó la importancia de este empleo como nexo entre el gobernador y la corporación, pero observaba que no en todas las ocasiones llegó a haberlos, y que no era raro que uno de los alcaldes ordinarios fuese designado para ocupar el $\operatorname{cargo}^{\underline{7}}$.

No todos los gobernadores se hicieron representar por sus tenientes en el Cabildo de Buenos Aires. En 1690, último año del gobierno de Joseph de Herrera y Sotomayor, su teniente Pedro de Vera y Aragón presenció 28 de las 30 sesiones que se celebraron. Esos altísimos niveles de concurrencia no volverían a repetirse. En 1693, Agustín de Robles nombró teniente al licenciado Francisco Bustillo, 
un antiguo abogado de la Real Audiencia de Chuquisaca, pero en julio de ese año el Cabildo denunció a este sujeto por la vida escandalosa que llevaba -se rumoreaba que tenía una concubina mulata y que había sido visto frecuentando durante la noche a mujeres de dudosa reputación en los arrabales de la ciudad- y le solicitó que por su poca aplicación al empleo lo exonerase del cargo. En enero del año siguiente, el gobernador lo reemplazó por uno de los alcaldes ordinarios, Baltasar de Quintana Godoy. De allí en más, tanto Robles como sus sucesores Prado y Maldonado y Valdés Inclán depositaron el ejercicio de este empleo en los alcaldes ordinarios de primer voto. Los mismos se vieron tan sobrecargados de trabajo que en 1707 la corporación tuvo que solicitar a la Real Audiencia de Chuquisaca que prohibiera que se los volviera a designar en el cargo, y consiguió que ésta fallara a su favor ${ }^{8}$.

A partir de ese incidente ya no hubo en Buenos Aires tenientes de gobernador hasta 1715, cuando Baltasar García Ros -reflotando la antigua costumbre- confirió el empleo al alcalde ordinario Tomás de Arroyo, y arguyó que había sido “estilo practicable que hagan este oficio los alcaldes de Primer Voto”․ . Pero al año siguiente lo reemplazó por un cabildante que desempeñaba un oficial venal, el alcalde provincial de la Hermandad Joseph Ruiz de Arellano: se trataba de un navarro que formaba parte de su círculo más íntimo de allegados $\underline{10}$. Bruno Mauricio de Zavala también escogería como teniente a un personaje de su entorno, Antonio de Larrazábal, quien aunque había sido anteriormente cabildante era entonces ajeno a la corporación, algo que no ocurría en Buenos Aires desde hacía más de tres décadas. Larrazábal tendría un respetable nivel de concurrencia al ayuntamiento, pues acudió en 28 ocasiones en 1724 y en 17 en 1725, equivalentes al 38,8 y 28,8 \% de las sesiones celebradas en esos años, todas ellas mientras Zavala se encontraba fuera de la ciudad.

A lo largo de más de un siglo los tenientes de gobernador habían sido investidos con el título de Teniente General y Capitán a Guerra. Esta denominación aludía al eventual carácter militar que originariamente se le otorgara a este cargo, pues se preveía que encabezara la defensa de la ciudad en el caso de que el gobernador debiera movilizarse a causa de una contienda bélica. Pero, como ya hemos referido, la cobertura de esas vacancias había pasado a ser desempeñada desde 1680 por el comisario de la caballería, y desde 1717 por el teniente de rey. Hasta 1687 se les otorgó el derecho, expresado en sus nombramientos, de presentarse en público empuñando un bastón, considerado una insignia del poder militar. En las décadas que siguieron continuarían exhibiendo ese ornamento en virtud a la costumbre, aunque dejó de hacerse alusión a él en las designaciones. Si bien prestó poca atención a los emblemas de poder, Zavala quiso poner fin a la ambivalencia del título. Al nombrar a Antonio de Larrazábal "lugarteniente de lo Político de esta ciudad” circunscribió su actuación a la instancia del gobierno civil y le encargó además que lo auxiliara en la administración de la justicia ordinaria.

\section{Una querella protocolar en torno a un emblema de poder}

En el verano de 1724, Zavala pasó con una compañía de milicianos a la Banda Oriental a expulsar a una partida de portugueses que había pretendido fundar un asentamiento en la bahía de Montevideo. Al asumir el mando político durante su ausencia, Larrazábal aprovechó para examinar las finanzas del ayuntamiento. La corporación contaba usualmente con recursos limitados, pero en 1723, luego 
de largas negociaciones, el Real Asiento británico había aceptado liquidar las deudas que tenía con ella, abonando la alícuota que le correspondía por la carga de cueros en los buques negreros y los derechos de anclaje. Con esas entradas la caja municipal, hasta entonces deficitaria, pudo afrontar tareas pendientes como la reedificación del edificio del cabildo y el reparto de limosnas entre viudas y huérfanos. Pero parte de esos fondos corporacionales acabó siendo desviada por los cabildantes para especular con ellos, implicándolos en préstamos a terceros. Enterado de ello, Larrazábal los acusó de defraudación y los conminó a que en un plazo de treinta días restituyeran las sumas faltantes. También les ordenó que designasen dos diputados para que presentaran cuentas de la administración de esos fondos, con la exigencia de que ninguno se excusase de asistir el día que se acordara su nombramiento. Los cabildantes, no obstante, recurrieron a una de sus acostumbradas estratagemas: la de posponer el tratamiento del asunto $\underline{11}$.

Impedir a los cabildantes que especularan con los fondos corporacionales equivalía a restarle rentabilidad a sus empleos. La mayoría de los oficiales concejiles detentaban empleos venales como el de regidor, alférez real, alguacil mayor o alcalde provincial de la Hermandad, todos ellos adquiridos en subasta. En una ciudad pequeña como era entonces Buenos Aires, esos oficios arrojaban beneficios exiguos, consistentes en la imposición de multas y el cobro de comisiones, los cuales también serían puestos en entredicho por Larrazábal $\underline{12}$. Al intentar combatir unas conductas que juzgaba reprobables pero que no dejaban de ser habituales en el ejercicio de las magistraturas comunales, éste pretendía que el desempeño de esos cargos fuera sólo valorado por la honra que otorgaban a quienes los detentaban, ya que consideraba que honor y rédito económico resultaban incompatibles al desempeñar un oficio concejil.

Este enfrentamiento encontraría otro canal de expresión en un problema de etiqueta. Larrazábal se había exhibido en público empuñando un bastón, insignia distintiva del poder militar, siendo que solamente se le había delegado el gobierno en lo político, es decir, el mando civil. Con ello se trastocaban los valores cortesanos que otorgaban al uso de las insignias las capacidades de señalar el lugar que tocaba a cada corporación o magistrado en el orden jerárquico y de indicar hasta dónde se extendía su jurisdicción. Esos valores, como es sabido, no sólo pautaban el comportamiento de los individuos en las cortes virreinales, sino también en una corporación municipal situada en los márgenes de los territorios de la Monarquía, como lo era el cabildo de Buenos Aires, aunque asumían en cada caso caracteres distintivos (Cárdenas Gutiérrez, 2013; Bridikhina, 2007).

El conflicto se suscitó cuando el prior del convento de La Merced invitó a los cabildantes a participar de una misa en honor a San Pedro Nolasco. El evento no formaba parte de las llamadas fiestas de tabla, a las que estaban obligados a concurrir, pero Larrazábal igualmente los forzó a hacerlo, amenazando a los inasistentes con una multa de 200 pesos. Su intención era la de colocarse visual y simbólicamente a la cabeza del Cabildo, y encuadrar a sus miembros tras de sí durante la ceremonia religiosa. Éstos terminaron por someterse a su intimación, pero desobedecieron a Larrazábal en un punto: en contra de lo que éste había ordenado, se desplazaron por las calles de la ciudad haciéndose preceder por dos menestrales que enarbolaban las mazas, bastones de plata que simbolizaban al Cabildo como cuerpo. Concurrían así "en forma de ciudad”, es decir, no como una suma de individualidades, sino como una corporación cuya autonomía quedaba afirmada por medio de ese gesto. $\mathrm{Al}$ hacer alarde de esos ornamentos le demostraban, además, que no renunciarían a 
exhibir los emblemas que los representaban frente a la vecindad $\underline{13}$.

En la entrada de la iglesia conventual se encontraron con Larrazábal, vestido con traje militar y empuñando un bastón, quien salió a recibirlos fuera del pórtico. Se produjo allí un episodio lleno de tensión: Miguel Rodríguez de Sosa, el alcalde ordinario de primer voto le preguntó escandalizado si se proponía entrar con el bastón a la misa. Aquél se limitó a contestarle: “¿No lo ve usted?”. Ante esa respuesta los cabildantes amenazaron con retirarse, pero él se dirigió a ellos con firmeza y les ordenó: "Entren ustedes y no causen escándalo”. Le preocupaba, evidentemente, cómo habría de repercutir en la vecindad este tenso diálogo, que había sido presenciado por otras personas que se agolpaban para ingresar al templo. Por considerarse agraviados, los cabildantes se negaron a obedecerlo y abandonaron el convento. Más tarde lo acusarían de haberles hablado "con imperiosa y destemplada voz" y de haber hecho uso de "desusadas como no experimentadas palabras": en definitiva, de haber faltado a las reglas de la cortesía y al respeto que les debía como magistrados. Ellos, en cambio, sostendrían que se habían dirigido a él "política y cortesanamente, sin destemplanza de voces ni otras demostraciones”. Larrazábal tuvo que resignarse a entrar solo a la iglesia y se sentó en el escaño que le estaba reservado. Dos regidores que ya estaban sentados en los suyos, al observar que llevaba consigo el bastón se levantaron y abandonaron el templo $\underline{14}$.

La escena se repitió pocos días después, cuando llegaron noticias de que la incursión de Zavala contra los portugueses había sido exitosa. Al celebrarse en la catedral una misa en acción de gracias, Larrazábal volvió a presentarse empuñando un bastón. A lo largo de varias sesiones, los cabildantes discutieron si con ello había controvertido o no las normas. Los integrantes de la facción mayoritaria lo acusaron de haberse opuesto a las costumbres de las ciudades del Río de la Plata y el Tucumán, donde los tenientes de gobernador acostumbraban mostrarse en público empuñando la vara de justicia y no un bastón militar, de acuerdo con lo que disponía la Recopilación de Leyes de los Reinos de Indias. No obstante, el parecer de los presentes no fue unánime. Ocho de ellos votaron que se lo debía intimar a deponer su actitud, mientras que dos regidores -Baltasar de Quintana Godoy y Pedro Zamudio, que representaban lo que quedaba de la antigua facción de los Samartín y estaban emparentados con la esposa de Larrazábal- proclamaron que éste había actuado siempre según su derecho.

El teniente de gobernador reaccionó desarmando este foco de resistencia. El 20 de marzo de 1724 escarmentó a los cabildantes que habían votado en su contra exonerándolos de sus cargos, y además los confinó provisoriamente en sus casas y les impuso una multa de 200 pesos. Las varas de los alcaldes ordinarios y del alcalde provincial, que fueron suspendidos en sus funciones, fueron entregadas a tres regidores que quedaron en ejercicio de sus empleos a fin de que no quedara interrumpida la administración de los distintos ramos de justicia.

\section{Poniendo Ilave a una puerta: unas palabras finales}

Los integrantes del Cabildo se hallaban sujetos a un conjunto de normas de conducta que, aunque estaban consagradas por la costumbre, habían sido recogidas por las ordenanzas de la corporación. Las mismas, que reflejaban la estructura jerárquica del cuerpo, les indicaban cómo debían comportarse de acuerdo con las preeminencias que correspondían a sus $\operatorname{cargos} \underline{15}$. En torno a la 
interpretación de esas normas se habían generado tensiones recurrentemente, tanto entre sus mismos integrantes como entre estos y los agentes de la Monarquía. La querella que hemos descripto, generada por el uso de una insignia, no fue sino una de tantas que había vivido el Ayuntamiento a lo largo de poco más de un siglo de existencia, pero fue la primera en ser coronada por una purga de los miembros de la planta concejil.

Al regresar de la Banda Oriental, Zavala convalidó la decisión de Larrazábal y no reincorporó a los cabildantes exonerados. Dos de los integrantes de la facción sediciosa, Joseph Ruiz de Arellano y Juan Vicente de Vetolaza y Luna -el primero, privado de su cargo, y el segundo aún en ejercicio- se presentaron en los estrados a asumir la representación de sus compañeros. La corporación, arguyeron éstos, había respetado tanto la normativa de la corona como las prácticas consuetudinarias locales, no pudiendo considerarse un delito "el observar y cumplir las prescriptas leyes de Nuestro Católico Monarca y natural señor, ni guardar las establecidas ordenanzas y costumbres de una República Política y Cristiana”. Hacían así alusión al gobierno comunal en su carácter de República, habilitado para exigir el cumplimiento de las leyes en defensa del orden y la prosperidad del colectivo al que representaba: la vecindad (Lempérière, 2013). Y culparon al gobernador de haber desobedecido los procedimientos recientemente establecidos por la Corona para los casos de vacancia, los cuales estipulaban que en caso de ausencia del gobernador, tanto el mando político como el militar debían depositarse en el teniente de rey y, a falta de éste, en el sargento mayor de más antigüedad del Presidio.

En respuesta a esta acusación, Zavala lanzó un auto de gobierno por el que les ordenó que en adelante se abstuvieran interpretar las disposiciones del monarca, atribuyéndose a sí mismo facultades exclusivas para hacerlo $\underline{16}$. No les quedó otra opción que valerse de las vías recursivas que les ofrecía la justicia, encargando a Ruiz de Arellano que viajara a la ciudad de Chuquisaca para peticionar ante la Real Audiencia. Ambas partes se enfrentarían ante ese alto tribunal altoperuano. Larrazábal se sirvió allí de la pluma de un procurador, quien reprodujo en su discurso los mismos argumentos y el mismo sistema de representaciones del que se había valido el monarca al reformar la estructura del gobierno en el Río de la Plata. Afirmó que con la expulsión de los cabildantes se quiso dar fin a las discordias intestinas, que podían ser aprovechadas por las potencias rivales. Si en cualquier ciudad debía existir la concordia entre el Cabildo y los representantes del rey,

...con más especialidad en Buenos Aires por ser Presidio y Llave de este Reyno y estar en fronteras en donde pueden temerse invasiones de enemigos, deben sus habitadores estar con más unión y con más ciega obediencia a los preceptos justos del superior, sin fomentar parcialidades perniciosas y opuestas a la tranquilidad y sosiego de la República.

Aludió, asimismo, a las recientes medidas tomadas por la Corona, que al limitar al ayuntamiento a desempeñar su rol de corporación municipal, lo habían privado de cualquier otra función que excediera ese nivel de actuación. Acusó a los cabildantes de haber querido sobrepasar a los representantes del rey, acción temeraria que equivalía a haber pretendido aventajar al mismo monarca, ya que, además, desde 1715 el Ayuntamiento carecía de atribuciones fuera del ámbito del gobierno municipal. Argumentó, en efecto, que "reside en el soberano todo el poder, no quedando 
en los cabildos ni más jurisdicción ni más facultad que en algunas cosas menores y siempre subordinado a lo que mandare el Príncipe”. El defensor de Larrazábal recurrió a una paráfrasis comúnmente empleada por los tratadistas, que aludía a un suceso remoto pero emblemático: el pacto entre el Senado Romano y el César. Desde que en Roma el pueblo confiriera a su príncipe toda su potestad, "reside en el soberano todo el poder, no quedando en los Cabildos ni más jurisdicción ni más facultad que en algunas cosas menores y siempre subordinado a lo que mandare el Príncipe”플 Esta estrategia argumentativa buscaba asestar un golpe a la causa de los cabildantes expulsados, ya que éstos no podían poner en cuestión la supremacía jurisdiccional del monarca. Pese a la considerable autonomía de que gozaban las ciudades en la Monarquía hispánica, se consideraba que todo poder ejercido en el espacio municipal era una concesión del soberano. Aunque cada ciudad gozara de un espectro de capacidades políticas propias, surgidas muchas de ellas del derecho consuetudinario, esas prácticas jurídicas y los derechos de autorregulación aparecían como si hubiesen sido otorgados por el rey (Agüero, 2005, pp. 132-136).

El pleito no se resolvería hasta 1730, año en que la Real Audiencia ordenó restituir a los cabildantes suspendidos sus escaños en el ayuntamiento. No obstante su derrota final, no puede negarse que la intervención de Larrazábal, convalidada por Zavala, fue un paso dado por los agentes de la Monarquía para moderar a la dirigencia concejil porteña, acostumbrada desde el siglo anterior a aproximarse a los gobernadores con el propósito de compartir con ellos los beneficios de la corrupción administrativa y el contrabando. Durante los gobiernos anteriores, los enfrentamientos facciosos en el seno de la corporación municipal habían puesto en evidencia que unos se encontraban mejor posicionados que otros para sacar rédito de esas componendas, lo que generaba la reacción de quienes quedaban apartados de ellas. Pero tanto García Ros como Zavala se opusieron a privilegiar a un sector de la vecindad y favorecer de esa forma el faccionalismo. Prefirieron designar a uno de sus allegados como teniente de gobernador para que supervisara la actuación de los miembros de la corporación sin inclinarse por ninguna de las coaliciones personales que pudieran existir en el interior de ésta.

Zavala, por otra parte, no ignoraba que, para aplicar el plan de gobierno que se le había confiado, iba a ser necesario desarmar a ese cabildo que se mostraba capaz de hacer frente a sus imposiciones. No se detuvo luego de la expulsión de los cabildantes y amenazó con quitarle al ayuntamiento los fondos que se le habían destinado para reconstruir un nuevo edificio para la corporación y destinarlos a la fundación de Montevideo $\underline{18}$. Posteriormente pretendió hacer un recorte a las potestades corporacionales y prohibió que se otorgaran licencias a los vaqueadores -es decir, a quienes capturaban ganado cimarrón- sin que mediara su aprobación. El Cabildo se opuso tenazmente a esto, recordándole que se encontraba en "posesión inmemorial” de esa facultad $\underline{19}$. Aunque finalmente no lo despojó ni de sus caudales ni de esas facultades, reconfirmó a Larrazábal como teniente de gobernador y lo hizo presidir las sesiones, por lo que todas las decisiones que tomase en adelante la corporación seguirían siendo supervisadas por éste.

Cuando a fines de 1724 el gobernador se vio obligado a trasladarse con sus tropas a Asunción del Paraguay, donde había estallado la rebelión de los comuneros, no volvió a depositar el mando supremo en Larrazábal, sino que decidió que durante su ausencia el mando político y militar fuera confiado a otro “cántabro”, el teniente de rey Baltasar García Ros. Decisiones como las anteriores 
podrán interpretarse como el triunfo de una red de vínculos paisanales por sobre las acostumbradas alianzas con las parentelas influyentes locales. Pero no queda duda de que reflejan también el acompañamiento que brindaron estos funcionarios a las directivas de la nueva dinastía reinante, decidida a reevaluar sus vinculaciones con las oligarquías urbanas y a subordinarlas a las políticas de la Corona.

En lo económico, en cambio, Zavala vino a apuntalar las concepciones tradicionales de la Monarquía. Este gobernador respondía a las directivas de Joseph Patiño, quien estaba a la cabeza de la Intendencia General de Marina y la Casa de Contratación, y fue el autor del Real Proyecto para Galeones y Flotas del Perú y Nueva España, en el que se reafirmó la tradicional Carrera de Indias, conservando a Buenos Aires en un lugar marginal. Patiño fue el último sostenedor del vetusto sistema de navegación atlántico impuesto por los Habsburgo, pues defendió en América la pervivencia de una estructura administrativa basada en dos enormes virreinatos que se hallaban conectados con la península a través del muy cuestionado sistema de flotas y galeones (García Baquero, 2001). En la concepción de este funcionario, la presencia española en el Río de la Plata se sostenía por la importancia que se daba a la región como bastión militar frente al avance portugués, y se la debía apuntalar mediante el asentamiento de una nueva población en los márgenes del estuario. Por tal razón encargó a Zavala la fundación de la ciudad de Montevideo, gracias a la cual los españoles se posicionaron firmemente a ambos lados del estuario, pero, a cambio de ello, la ciudad de Buenos Aires debió renunciar a sus pretensiones territoriales en la totalidad de la Banda Oriental. Hasta entonces, los vaqueadores porteños habían podido adentrarse en ella sin otro obstáculo que no fuera el temor a sufrir un ataque de los minuanes u otras etnias locales no sometidas. Pero en 1726, Zavala asignó a Montevideo un dilatado territorio que se extendía desde la desembocadura del arroyo de Cufré hasta las sierras de Maldonado y la Cuchilla Grande. Los cabildantes porteños, luego de sufrir la purga de la mitad de sus miembros, no se atreverían a oponer resistencia alguna contra una medida que acarreó para Buenos Aires un significativo recorte en su proyección territorial.

\section{Notas}

1 Hoy día se coincide en atribuir este libelo a Victorino Montero, marqués de Piedra Blanca. Se encuentra una copia del mismo en el Archivo General de la Nación [en adelante AGN] Manuscritos de la Biblioteca Nacional 7219 Estado político del Reino del Perú.

$\underline{2}$ El sistema de Reales Situados cuenta con una descripción general en Marichal y Souto Mantecón (1994), mientras que el caso novohispano ha sido descrito por Reichert (2012) y el rioplatense por Saguier (1989) y Birocco (2015a).

$\underline{3}$ Respecto de la metodología y fuentes utilizadas en este primer subcapítulo, remitimos al lector a nuestra tesis de doctorado, de cuyo enfoque sobre los vínculos políticos es un apretado resumen (Birocco, 2015b). 
4 A.G.N. IX-48-8-1, Escribanías Antiguas, f.145v.

$\underline{5}$ En 1707, Valdés Inclán nombró teniente al alcalde Luis Pesoa de Figueroa e interrogó a varios vecinos si éste había "ejercido algunos actos de la jurisdicción privativa que toca al Teniente General como son conocer en causas de grado de apelación de los Alcaldes Ordinarios”. Los testimonios coincidieron en que no habían visto a ningún teniente de gobernador desempeñar el rol de juez de apelaciones. AGN IX-42-2-7 Real Audiencia, sobre una información.

$\underline{6}$ Archivo del Extinto Cabildo de Buenos Aires [en adelante AECBA] Serie I, Tomo XVII, Págs. 368-370.

Z AGN IX-19-3-2 Archivo del Cabildo de Buenos Aires (1780-1783).

8 AGN IX-42-2-7 Real Audiencia, sobre una información.

9 AECBA Serie II, Tomo III, Págs. 204-205.

10 AECBA Serie II, Tomo III, Págs. 272-273.

11 AECBA, Serie II, Tomo V, pág. 293.

$\underline{12}$ No existe una evaluación general sobre la estipendio de los funcionarios del rey en el Río de la Plata, pero sí para otras regiones de la América española, por ejemplo en Gayol (2016).

13 AECBA Serie II Tomo V 255-262.

14 IX-42-9-2 Bruno Mauricio de Zavala, actos varios de su gobierno (1724).

15 No es el objetivo de este artículo ahondar sobre las prácticas rituales que regulaban los comportamientos de los integrantes del Cabildo. Un análisis de los mismos podrá hallarse en Cañeque (2004) y Smietniansky (2010).

16 La orden de Zavala fue taxativa y expresaba textualmente que "se les apercibe a los susodichos que en lo de adelante no se entrometan en querer interpretar las órdenes reales...”.

17 IX-42-9-2 Bruno Mauricio de Zavala, actos varios de su gobierno (1724).

18 AECBA Serie II, Tomo V, Págs. 337-339.

19 AECBA Serie II, Tomo V, Págs. 354-356.

\section{Bibliografía}

Agüero, A. (2005). Ciudad y poder político en el Antiguo Régimen. La tradición castellana. Cuadernos de Historia Academia Nacional de Derecho y Ciencias Sociales de Córdoba, Vol. 15, pp. 127-163.

Barriera, D. (2003). La historia del poder político sobre el periodo temprano colonial rioplatense. Razones de una ausencia. Propuestas para una agenda, Penélope, 29, 133-159.

Birocco, C. M. (1996). Historia de un latifundio bonaerense: las estancias de Riblos en Areco, 
1713-1813. Anuario de Estudios Americanos LIII, 1, 73-99.

Birocco C. M. (2011a). La pesquisa de Mutiloa en Buenos Aires. Conformación de facciones y lucha por el poder en el cabildo porteño. En P. Polimene (comp.), Autoridades y prácticas judiciales en el Antiguo Régimen. Problemas jurisdiccionales en el Río de la Plata, Córdoba, Tucumán, Cuyo y Chile (pp. 33-55). Rosario: Prohistoria,

Birocco, C. M. (2011b). En torno a la “anarquía” de 1714. La conflictividad política en Buenos Aires a comienzos del siglo XVIII. Anuario del Instituto de Historia Argentina, 11, 71-98.

Birocco, C. M. (2015a). El Presidio de Buenos Aires entre los Habsburgo y los Borbones: el ejército regular en la frontera sur del imperio español (1690-1726). En E. Reitano y P. Possamai (coord.), Hombres, poder y conflicto. Estudios sobre la frontera colonial sudamericana y su crisis (pp. 117150). FaHCE-Universidad Nacional de La Plata,.

Birocco, C. M. (2015b). La élite de poder en Buenos Aires colonial: cabildo y cabildantes entre los Habsburgos y los Borbones (1690-1726) (Tesis de doctorado), UNLP, La Plata, Argentina.

Brennot, A. M. (1989). L'étude du non pouvoir dans Estado Político del Reyno del Perú, V. Montero del Águila, 1742. Histoire, économie et société. 2, 167-197.

Bridikhina, E. (2007). La ciudad y la corte como espacios de poder en Hispanoamérica. La Plata colonial. Revista de Indias, 240 (LXVII), 553-572.

Cañeque, A. (2004). De sillas y almohadones o de la naturaleza ritual del poder en la Nueva España de los siglos XVI y XVII. Revista de Indias, 232 (LXIV), 609-634.

Cárdenas Gutiérrez, S. (2013). Las insignias del rey: Disciplina y ritual público en la ciudad de México (siglos XVI-XVIII). Jahrbuch für Geschichte Lateinamerikas, 40(43), 193-216.

Gammalsson, H. (1980). Los pobladores de Buenos Aires y su descendencia. Municipalidad de la ciudad de Buenos Aires.

García Baquero, A. (2001). El comercio colonial en la época de Felipe V: el reformismo continuista. En E. Serrano, Felipe Vy su tiempo. Zaragoza, Tomo I.

Gayol, V. (2016). La Retribución de los hombres del Rey. Aranceles y derechos de los oficiales públicos en la Nueva España del siglo XVIII. En J. L. Soberanes Fernández y O. Barney (coords.), Historia del Derecho. X Congreso de historia del derecho mexicano (pp. 26-48). México: UNAM,

Giménez López, E. (1994). El debate civilismo-militarismo y el régimen de Nueva Planta en la España del siglo XVIII. Cuadernos de Historia Moderna, Vol.15, pp. 41-75.

Guerra, F. X. (2004). De la política antigua a la política moderna. La revolución de la soberanía. En F. X. Guerra y A. Lempérière [coords], Los espacios públicos en Iberoamérica: ambiguedades y problemas, siglos XVIII-XIX. México: Fondo de Cultura Económica.

Guerrero Elecalde, R. (2012). Las élites vascas y navarras en el gobierno de la Monarquía Borbónica. Redes sociales, carreras y hegemonía en el siglo XVIII (1700-1746). Bilbao: Universidad del País Vasco. 
Jumar, F. (2000). Le commerce atlantique au Río de la Plata, 1680-1778 (Tesis de Doctorado), École des Hautes Études en Sciences Sociales, París, Francia.

Lempérière, A. (2013). Entre Dios y el rey: la republica: la ciudad de México de los siglos XVI al $X I X$. México: FCE.

Marichal, C. y Souto Mantecón, M. (1994). Silver and Situados: New Spain and the financing of the Spanish Empire in the Caribbean in the eighteenth century. Hispanic American Historical Review, 74(4), 587-613.

Moutoukias, Z. (1988). Contrabando y control colonial en el siglo XVII. Buenos Aires: Centro Editor de América Latina.

Moutoukias, Z. (2002). Las formas complejas de la acción política: justicia corporativa, faccionalismo y redes sociales (Buenos Aires, 1750-1760). Jahrbuch für Geschichte Lateinamerikas, Köln/Weimar/Wien, 39, 69-102.

Oliva Melgar, J. M. (1996). Realidad y ficción en el monopolio de Indias: una reflexión sobre el sistema imperial español en el siglo XVII. Manuscrits: revista d'història moderna, 14, 321-355.

Reichert, R. (2012). El situado novohispano para la manutención de los presidios españoles en la región del Golfo de México y el Caribe durante el siglo XVII. Estudios de historia novohispana, 46, 556-631.

Saguier, E. (1989). La conducción de caudales de oro y plata como mecanismo de corrupción. El caso del situado asignado a Buenos Aires por las Cajas Reales de Potosí en el siglo XVIII. Historia (Universidad Católica de Chile), Vol. 24.

Sanz Tapia, A. (2005). Andaluces en cargos políticos hispanoamericanos (1674- 1700). En A. Gutiérrez Escudero y M. L. Laviana Cuetos (coord.), Estudios sobre América, siglos XVI-XX: Actas del Congreso Internacional de Historia de América (pp. 614-644). Asociación Española de Americanistas, Sevilla.

Smietniansky, S. (2010). De preeminencias, estilos y costumbres: rituales y poder en los cabildos coloniales. Una aproximación etnográfica al análisis de materiales de archivo. Revista Colombiana de Antropología, 46(2), 379-408.

Tau Anzoátegui, V. (2003). Poderes y normas a través de un ejercicio de casuística indiana (Buenos Aires, 1714-1717). En L. E. González Vales (coord.), XIII Congreso del Instituto Internacional de Historia del Derecho Indiano: Actas y estudios (pp. 90-125), Vol. 1. Academia Puertorriqueña de la Historia.

Tarragó, G. (2010). Las venas de las Monarquía. Redes sociales, circulación de recursos y configuraciones territoriales. El Río de la Plata en el siglo XVIII. En J. M. Imízcoz y O. Oliveri (coord.), Economía doméstica y redes sociales en el Antiguo Régimen (pp.177-210). Madrid: Sílex.

Tarragó, G. (2014). Espacios de tensión, territorios en construcción. Santa Fe y Buenos Aires durante la primera etapa borbónica (1700-1745). En D. Barriera y R. Fradkin (coords.), Gobierno, justicias y milicias. La frontera entre Buenos Aires y Santa Fe, 1720-1830 (pp. 41-70). Universidad 
Nacional de La Plata.

Trujillo, O. (2012). Consenso, negociación y conflicto en la Monarquía Hispánica: La élite de Buenos Aires en el XVII (Tesis de Doctorado), Universidad Nacional de Luján, Luján, Argentina. 